\title{
Infiltrating Breast Carninomas Multifocality: Clinical and Biological Features
}

\author{
A. Ruibal ${ }^{1}$, M. Herranz ${ }^{*}, 2$, J. Cortes ${ }^{1}$, P. Menendez-Rodriguez ${ }^{3}$ and J.I. Arias ${ }^{4}$ \\ ${ }^{I}$ Radiology and Physical Medicine, Faculty of Medicine, Nuclear Medicine Head, Complejo Hospitalario Universitario, \\ 15706 Santiago de Compostela, Spain \\ ${ }^{2}$ Molecular Oncology and Imaging Program Director, Complejo Hospitalario Universitario, 15706 Santiago de \\ Compostela, Spain \\ ${ }^{3}$ Pathology Service. Hospital Central de Asturias, Oviedo, Spain \\ ${ }^{4}$ Surgery Service. Hospital Monte del Naranco, Oviedo, Spain
}

\begin{abstract}
In order to know the associations between multifocality (MF), without related multicentricity (MC), and common clinical and biological parameters, and posterior influence in breast carcinoma behavior, we have developed this study. 816 successive women affected from invasive breast carcinomas, of which 96 were multifocal and 720 nonmultifocal were included in the study. We considered age, size, lymph node involvement, distant metastasis, histological grade, ploidy, cellular synthesis phase, as well as expression of estrogen receptor (ER), progesterone receptor (PgR), androgen receptor (AR), p53, bcl2 and Ki67 by immunohistochemical assays.

Taken as a whole, multifocal invasive carcinomas $(11 \%)$ showed exclusively more distant metastasis and more tumorrelated-deaths. However, when tumors were classified according to histological type, in ductal carcinomas MF courses exclusively with greater lymph node involvement, while in non ductal carcinomas MF showed higher percentage of distant metastasis, higher proliferation and higher number of recurrences. Also, there were NO differences between axillary lymph node involvement and tumor size in multifocal tumors regardless of histology.

Our results suggest: 1) MF was found in $11 \%$ of invasive breast carcinomas and was associated with higher distant metastasis and number of tumor-related-deaths. 2) in invasive ductal carcinomas, MF was associated, exclusively, with increased axillary node involvement, whereas in other histological types, with a predominance of lobular, it did with higher distant metastasis, cell proliferation and recurrence number, suggesting, in this subtype of tumors where there is higher prognostic/diagnostic value has the MF presence.
\end{abstract}

Keywords: Infiltrating, breast carninomas, multifocality.

\section{INTRODUCTION}

Breast carcinoma is one of the most common tumors in daily practice and is usually associated with multifocality and multicentricity, mainly due to the use of new imaging technology for diagnosis. While some useful prognostic factors in these tumors are clinically well established [1-7], less known and controversy is the multifocality, which is not always well defined from a conceptual point of view [8-9] and often analyzed and associated with multicentricity. Also, tumor size is still under discussion [10] which one considered, the larger lesion or the sum of all lesions; it seems that the first option shown has superior clinical utility [11-12]. Multifocality seems to be genetically linked to chromosome 2 gains and losses on chromosome 15 [13]. Also, correct diagnosis is important for surgical approach and, although it is associated with an increased risk (20\%) of

*Address correspondence to this author at the Molecular Oncology and Imaging Program Director, Complejo Hospitalario Universitario, 15706 Santiago de Compostela, Spain; Tel: +34981955165;

Fax:+34981951437; E-mail: michel.herranz.carnero@sergas.es lymph node involvement, prognostic value is not fully defined, so further studies are needed to precise it [14].

We define multifocality as "existence of two or more invasive tumor foci separated by benign tissue in the same quadrant", using the larger size and not the sum of the lesion sizes $[15,16]$. In this study, we aimed to present our experience, comparing multifocality, separated from multicentricity, with other clinical and biological parameters, and analyzed the influence on breast carcinoma patients through monitoring, classified according to the major histological subtypes

\section{MATERIAL AND METHODS}

The cohort included 816 women affected from invasive breast carcinomas where 96 were multifocal (74 ductal carcinomas, 15 lobular, 3 cystosarcoma, 3 mucinous and 1 medullary) and 720 non-multifocal (605 ductal carcinomas, 46 lobular, 5 cystosarcoma, 30 mucinous, 15 medullar, 2 adenocystic, 6 apocrine, 17 tubular and 2 inflammatory). All were diagnosed between 1992 and 2009, in the Hospital Monte de Naranco (Oviedo, Spain), where the breast pathology unit and breast screening unit were located. 
We considered age, lymph node involvement $(\mathrm{N})$, distant metastasis (M), histological grade (HG), ploidy and cellular synthesis phase (SP), determined by flow cytometry in fresh samples (Fascam. Beckton-Dikinson. USA), and expressions of estrogen receptor (ER phramDx, 1D5/ER-2-123, Dako, Denmark), progesterone receptor (PR; 1294, Dako) androgen receptor (AR; 441, Dako, dilution 1/150), p53 (D0-7, Dako, dilution 1/100), bcl-2 (124; Dako, dilution 1/150) and Ki67 (MIB1, Dako, dilution 1/200), evaluated by immunohistochemical assays, using monoclonal antibodies. Immunohistochemical staining on tissue sections of 4-5 microns was done by the EnVision method with a heatinduced antigen retrieval step. Sections were immersed in boiling $10 \mathrm{nmol} / \mathrm{L}$ sodium citrate at $\mathrm{pH} 6,5$ for 2 minutes in a pressure cooker.

ER and PR were assessed according to the Allred score, negatives (score: $0-2$ ) and positives (score: $3-8$ ). Cut-offs for p53 and Ki67 positivity were $30 \%$ and $15 \%$, respectively. AR was classified as positive or negative without any score, and bcl-2 as negative (-), weak positive (+) or strong positive $(++)$.

Performed treatment was surgery, preferably conservative, followed by chemotherapy, radiotherapy and hormone therapy. Checkups by the Surgery Department began when the treatment was completed. Follow-ups were quarterly or half yearly the first two years, depending on the severity, type of tumor and prognosis. After the second until the fifth year, checkups were six-monthly, and, thereafter, annually with exceptions.

Windows SPSS software was employed for statistical analysis. Continuous variables with a Gaussian distribution were expressed as the range and the mean +/- SD (standard deviation), while, if not, were expressed as the range and the median. To validate any statistically significant difference, Chi-square distribution was used (with Yates correlation, if necessary). Survival curves were analyzed by Kaplan-Meier method and their difference by the log-rank test. The criteria to be considered as significant was $\mathrm{p}<0.05$.

\section{RESULTS}

a) Taken as a whole, and presented in Table 1, multifocal invasive carcinomas showed, exclusively, more distant metastasis $(\mathrm{p}=0.032)$. During the followup period, ranged from 1 to 196 months $(51.5+/-38.6$, median 44 months), multifocal carcinomas showed more tumor-related-deaths $(\mathrm{p}=0.002)$.

b) When tumors were classified according to histological type, we found in ductal carcinomas (see Table 2), multifocality courses exclusively with higher lymph node involvement (greater than 3), close to statistical significance, but there were NO differences in recurrence number and/or tumorrelated-deaths. By contrast, in non-ductal carcinomas (see Table 3), multifocality showed higher distant metastasis percentage $(4 / 22 v s 4 / 115, \mathrm{p}=0.021)$ and higher recurrence number $(4 / 16 v s 3 / 102, \mathrm{p}=0.0025)$.

c) Analyzing axillary lymph node involvement $(\mathrm{N})$ versus multifocality, tumor subtype and tumor size as described in Table $\mathbf{4}$ we observed NO difference between axillary lymph node involvement and tumor size in multifocality breast carcinomas regardless of histology. By contrast, in non-multifocal tumors, infiltrating ductal carcinomas coursed with more axillary involvement are independent of the size. Multifocal non-ductal carcinomas, smaller than $2 \mathrm{~cm}$, showed higher axillary involvement $(\mathrm{p}=0.043)$ than non-multifocal.

Table 1. Clinical and Biological Differences of Invasive Carcinomas with or without Multifocality

\begin{tabular}{|c|c|c|c|}
\hline Parameter & Multifocality & Non Multifocality & $\mathbf{p}$ \\
\hline $\mathrm{N}+$ & $45 / 96$ & $284 / 720$ & ns \\
\hline $\mathrm{N}+>3$ & $20 / 96$ & $113 / 720$ & ns \\
\hline $\mathrm{M}+$ & $16 / 96$ & $69 / 720$ & 0,032 \\
\hline GH3 & $31 / 96$ & $192 / 720$ & ns \\
\hline Aneuploidy & $14 / 33$ & $152 / 364$ & ns \\
\hline $\mathrm{ER}+$ & $56 / 67$ & $281 / 344$ & $\mathrm{~ns}$ \\
\hline $\mathrm{PR}+$ & $42 / 66$ & $207 / 342$ & ns \\
\hline $\mathrm{AR}+$ & $43 / 55$ & $209 / 257$ & $\mathrm{~ns}$ \\
\hline P53+ & $14 / 59$ & $63 / 300$ & ns \\
\hline Bcl-2++ & $43 / 57$ & $214 / 277$ & ns \\
\hline $\mathrm{Bcl}-2+++$ & $34 / 57$ & $185 / 277$ & ns \\
\hline Ki67+ & $38 / 69$ & $176 / 345$ & $\mathrm{~ns}$ \\
\hline$>2 \mathrm{~cm}$ & $41 / 96$ & $299 / 720$ & $\mathrm{~ns}$ \\
\hline$>5 \mathrm{~cm}$ & $5 / 96$ & $27 / 720$ & ns \\
\hline $\mathrm{SP}>7 \%$ & $16 / 31$ & $162 / 340$ & ns \\
\hline Age & $34-86(60,4+/-10,6)$ & $27-88(61,0+/-10,4)$ & $\mathrm{ns}$ \\
\hline Recurrences & $13 / 83$ & $56 / 541$ & ns \\
\hline Deaths & $9 / 79$ & $19 / 525$ & 0,002 \\
\hline \multicolumn{4}{|c|}{$\begin{array}{l}\text { N: lymph node involvement. } \\
\text { M: distant metastasis. } \\
\text { HG: histological grade. } \\
\text { ER: estrogen receptor. } \\
\text { PR: progesterone receptor. } \\
\text { AR: androgen receptor. } \\
\text { SP: cellular synthesis phase. } \\
\text { ns: non significant. }\end{array}$} \\
\hline
\end{tabular}

d) Analyzing distant metastasis (M) versus multifocality, histological subtype and tumor size, multifocal carcinomas, as showed in Table 5, spread increased with size in non-ductal while the same happen with ductal carcinoma in non-multifocal. Multifocal nonductal carcinomas with size greater than $2 \mathrm{~cm}$, showed higher distant metastasis than those without multifocality $(\mathrm{p}=0.00015)$.

e) Comparing multifocal carcinomas with each other, 74 ductal showed, exclusively, more axillary lymph node involvement $>3(1 / 22$ vs $19 / 74, \mathrm{p}=0.048)$, whereas 22 non-ductal showed a trend toward more recurrences and tumor-related-deaths, but without statistical significance, possibly by the small number of patients, (4/16 vs 6/67 and 4/16 vs 5/63). 
Table 2. Clinical and Biological Differences of Invasive Ductal Carcinomas with or without Multifocality

\begin{tabular}{|l|l|l|l|}
\hline Parameter & Multifocality & Non Multifocality & p \\
\hline \hline $\mathrm{N}+$ & $36 / 74$ & $254 / 605$ & $\mathrm{~ns}$ \\
\hline $\mathrm{N}+>3$ & $19 / 74$ & $102 / 605$ & 0,061 \\
\hline $\mathrm{M}+$ & $12 / 74$ & $65 / 605$ & $\mathrm{~ns}$ \\
\hline HG3 & $27 / 74$ & $182 / 605$ & $\mathrm{~ns}$ \\
\hline Aneuploidy & $9 / 23$ & $138 / 306$ & $\mathrm{~ns}$ \\
\hline ER+ & $45 / 54$ & $234 / 285$ & $\mathrm{~ns}$ \\
\hline PR+ & $33 / 53$ & $169 / 283$ & $\mathrm{~ns}$ \\
\hline AR+ & $37 / 46$ & $176 / 218$ & $\mathrm{~ns}$ \\
\hline P53+ & $14 / 49$ & $55 / 254$ & $\mathrm{~ns}$ \\
\hline Bcl-2+ & $35 / 47$ & $182 / 234$ & $\mathrm{~ns}$ \\
\hline Bcl-2++ & $26 / 47$ & $159 / 234$ & $\mathrm{~ns}$ \\
\hline Bcl-2+++ & $18 / 37$ & $104 / 171$ & $\mathrm{~ns}$ \\
\hline Ki67+ & $38 / 69$ & $176 / 345$ & $\mathrm{~ns}$ \\
\hline SP $>7 \%$ & $13 / 22$ & $140 / 285$ & $\mathrm{~ns}$ \\
\hline$>2 \mathrm{~cm}$ & $33 / 74$ & $246 / 605$ & $\mathrm{~ns}$ \\
\hline$>5 \mathrm{~cm}$ & $4 / 74$ & $18 / 605$ & $\mathrm{~ns}$ \\
\hline Age & $34-86(60,4+/-10,6)$ & $27-88(61,1+/-10,0)$ & $\mathrm{ns}$ \\
\hline Recurrences & $9 / 67$ & $53 / 439$ & $\mathrm{~ns}$ \\
\hline Deaths & $5 / 63$ & $18 / 425$ & $\mathrm{~ns}$ \\
\hline$:$ Iynp & & \\
\hline
\end{tabular}

$\mathrm{N}$ : lymph node involvement.

M: distant metastasis.

HG: histological grade.

ER: estrogen receptor.

PR: progesterone receptor.

AR: androgen receptor.

SP: cellular synthesis phase.

ns: non significant.

\section{DISCUSSION}

There are different definitions for multifocality, but one of the most accepted is the existence of two or more foci in the same quadrant. We have found this situation in 96 of 818 invasive breast carcinomas (11\%). Meanwhile positive levels reported in the literature goes between 13 and 75\% [13], our value is similar to Joergensen et al. (13.5\%) [9] and Coombs et al. (11\%) [10], higher than Jürgensen et al. (6.6\%) [17] and slightly lower than Pedersen et al. (17\%) [18]. Our rate is at the low limits, probably because our hospital is the reference center for breast cancer screening, so it can prevail over the initial stage tumors, as happens to other authors [10]. Multifocality percentage is closely related to the imaging techniques used to detection, from $15 \%$ with mammography to higher values (34\%) when ultrasound (19) or MRI [19-21] were used, although according to Bendifallah et al. [14], MRI could reflect many false positives, therefore, it is not recommended as the first-line technique. In women below 35 years, multifocality percentage is $19 \%$ [22].
Table 3. Clinical and Biological Differences of Invasive NonDuctal Carcinomas with or without Multifocality

\begin{tabular}{|c|c|c|c|}
\hline Parameter & Multifocality & Non Multifocality & $\mathbf{p}$ \\
\hline $\mathrm{N}+$ & $9 / 22$ & $30 / 115$ & ns \\
\hline $\mathrm{N}+>3$ & $1 / 22$ & $11 / 115$ & ns \\
\hline $\mathrm{M}+$ & $4 / 22$ & $4 / 115$ & 0,021 \\
\hline HG3 & $4 / 22$ & $10 / 115$ & ns \\
\hline Aneuploidy & $5 / 10$ & $14 / 58$ & ns \\
\hline $\mathrm{ER}+$ & $11 / 13$ & $47 / 59$ & ns \\
\hline $\mathrm{PR}+$ & $9 / 13$ & $38 / 59$ & ns \\
\hline $\mathrm{AR}+$ & $6 / 9$ & $33 / 39$ & ns \\
\hline P53+ & $0 / 10$ & $8 / 46$ & ns \\
\hline Bcl-2+ & $8 / 10$ & $32 / 43$ & ns \\
\hline $\mathrm{Bcl}-2++$ & $8 / 10$ & $26 / 43$ & ns \\
\hline Bcl-2+++ & $4 / 6$ & $19 / 35$ & ns \\
\hline Ki67+ & $6 / 13$ & $20 / 56$ & ns \\
\hline $\mathrm{SP}>7 \%$ & $3 / 9$ & $22 / 55$ & ns \\
\hline$>2 \mathrm{~cm}$ & $8 / 22$ & $53 / 115$ & ns \\
\hline$>5 \mathrm{~cm}$ & $1 / 22$ & $9 / 115$ & ns \\
\hline Age & $46-85(63,5+/-10,1)$ & $27-85(60,4+/-11,8)$ & ns \\
\hline Recurrences & $4 / 16$ & $3 / 102$ & 0,0025 \\
\hline Deaths & 116 & $1 / 100$ & ns \\
\hline
\end{tabular}

$\mathrm{N}$ : lymph node involvement.

$\mathrm{M}$ : distant metastasis.

HG: histological grade.

ER: estrogen receptor.

PR: progesterone receptor.

AR: androgen receptor.

SP: cellular synthesis phase.

ns: non significant.

Table 4. Distribution of Axillary Lymph Node Involvement in Invasive Carcinomas Classified According to Multifocality, Size and Histological Subtype

\begin{tabular}{|c|c|c|}
\hline \multicolumn{3}{|c|}{ Multifocal } \\
\hline & Ductal & Non-Ductal \\
\hline Size & $\mathbf{N}+$ & $\mathbf{N +}$ \\
\hline$<2 \mathrm{~cm}$ & $14 / 36(\mathrm{~A})$ & 6/15 (B) \\
\hline$>2 \mathrm{~cm}$ & $22 / 38(\mathrm{C})$ & $3 / 7$ (D) \\
\hline \multicolumn{3}{|c|}{ Non Multifocal } \\
\hline & Ductal & Non-Ductal \\
\hline Size & $\mathbf{N +}$ & $\mathbf{N +}$ \\
\hline$<2 \mathrm{~cm}$ & $77 / 298(\mathrm{E})$ & $8 / 57(\mathrm{~F})$ \\
\hline$>2 \mathrm{~cm}$ & $169 / 307(\mathrm{G})$ & $22 / 58(\mathrm{H})$ \\
\hline
\end{tabular}

B $v$ F: p: 0,043

E vs F: p:0,060.

G vs $\mathrm{H}: \mathrm{p}: 0,017$

E $v s \mathrm{G}:<0,0001$.

F vs H: p:0.003. 
Table 5. Distribution of Distant Metastasis in Invasive Carcinomas Classified According to Multifocality, Size and Histological Subtype

\begin{tabular}{|c|c|c|}
\hline \multicolumn{3}{|c|}{ Multifocal } \\
\hline & Ductal & Non-Ductal \\
\hline Size & $\mathbf{M +}$ & $\mathbf{M +}$ \\
\hline$<2 \mathrm{~cm}$ & 3/34 (A) & 1/16 (B) \\
\hline$>2 \mathrm{~cm}$ & 9/40 (C) & 3/6 (D) \\
\hline \multicolumn{3}{|c|}{ Non Multifocal } \\
\hline & Ductal & Non-Ductal \\
\hline Size & $\mathbf{M}+$ & $\mathbf{M +}$ \\
\hline$<2 \mathrm{~cm}$ & $16 / 331(\mathrm{E})$ & $2 / 43(\mathrm{~F})$ \\
\hline$>2 \mathrm{~cm}$ & 49/277 (G) & 2/72 (H) \\
\hline
\end{tabular}

D $v s$ H: p:00015.

B $v s$ D: $\mathrm{p}: 0,046$

E vs G: p: $<0,0001$

G vs H: p: 0,001.

When we analyzed clinical and biological differences of invasive breast carcinomas as a unique group, multifocal carcinomas showed, exclusive and statistically, increased distant metastasis and higher death rate. We found no association with size, especially those higher than $5 \mathrm{~cm}$, lymph node involvement, especially more than 3 nodes, premenopause, age $<40$ years, advanced histological stage and grade, as described by other authors [9, 10, 17]. There is no association between multifocality, tumor location and age, but only with bilaterality [17].

Joergensen et al. [9] explain association between multifocality and estrogen receptor (ER) expression. We found no differences when ER using immunohistochemical assays were analyzed, until it is determined in the cytosol by an enzyme immunoassay in 429 cases, 33 multifocal (range 1-605, median $31 \mathrm{fmol} / \mathrm{mg}$ prot.) versus 396 non-multifocal carcinomas (range 1-1240, median $18.2 \mathrm{fmol} / \mathrm{mg}$ prot.), $\mathrm{p}=0.043$. These differences were not observed with Progesterone Receptor (PR). In this regard, Garimella et al. [23] using immunohistochemical assays, described small differences in ER expression between different tumor foci, which do not affect the positive/negative final result, while PR showed higher variability.

About relationship between multifocality and disease prognosis, we found bigger number of tumor-related deaths in multifocal, but not the recurrences. In the literature, there is much disagreement, so, some authors relate it with disease-free interval (DFI), but not with overall survival (OS) $[9,24]$, some found no association with DFI or OS in 5 years monitoring $[17,25]$, or women age below 35 years [22]; and other authors found positive association with a worse survival [26], both in terms of recurrence and distant metastasis, being a prognostic factor after multivariate analysis $[10,27]$.

Boyages et al. [12], with a 10-year follow-up study, verify that multifocal carcinomas had higher number of tumor-related deaths $(\mathrm{p}=0.022)$; however, 10-year survival was not affected by tumor multifocality $</=2 \mathrm{~cm}$, but only in those higher than $2 \mathrm{~cm}$, where 10 years survival was $72.1 \%$ in unifocal and $54.7 \%$ in multifocal using the higher tumor size $(p=0.008)$, and $69.5 \%$ was and not significant, respectively, when tumors were classified adding all malignant foci sizes, the fact that supports the practical relevance of the first criterion.

However, these discrepancies could be due to histology that had not been validated separately, but together. To address this possibility we have analyzed the role of multifocality on histological subtypes. We have seem that in ductal carcinomas, multifocality is exclusively associated with increased lymph node involvement, but not with prognosis and/or evolution; however, in other subtypes, multifocality is related to distant metastasis, increased proliferation, higher recurrence number (See Fig. 1) and tumor-related deaths. Analyzing the other subtypes, lobular predominated (15 of 22), they were more frequently multifocal, multicentric and with higher size at the time of diagnosis, than the ductal carcinoma, which is frequently associated with positive boundaries after conservative surgery and radiotherapy [28], which may reflect higher biological aggressiveness and validate our findings.

In multifocal carcinomas there were no differences in regional axillary involvement when histological subtype and size were considered. However, in non-multifocal, percentage of axillary node involvement increase with tumor size and was higher in ductal carcinomas than in other histologies. Moreover, infiltrating non-ductal tumors below 2 $\mathrm{cm}$, showed higher axillary lymph node involvement, when they were multifocal.

All this reflects the fact that multifocal carcinomas have "per se" better capability to invade lymph nodes, which means could be "more aggressive" independently of tumor size, these details were also suggested by Cabioglu et al. [24]. When distant metastatis ability was measured, there were NO differences in terms of multifocal carcinoma histology, increased according to the size of non-ductal; however, in non-multifocal, ductal carcinomas were found to be associated with greater spread and size increasing, which is an opposite behavior observed in the multifocal cases.

Comparing multifocal carcinomas with each other, ductal are associated with increased lymph node involvement, whereas non-ductal with higher number of recurrences and tumor-related deaths. Furthermore, 33 ductal carcinomas had higher cytosolic ER concentrations than 14 non-ductal (range 1-605, median 31 vs 1-59, median $13.7 \mathrm{fmol} / \mathrm{mg}$ prot., respectively. $\mathrm{p}=0.004)$.

Our results suggest: 1) MF was found in $11 \%$ of invasive breast carcinomas and was associated with higher distant metastasis and number of tumor-related-deaths. 2) In invasive ductal carcinomas, MF was associated, exclusively, with increased axillary node involvement, whereas in other histological subtypes, with a predominance of lobular, it did with higher distant metastasis, cell proliferation and recurrence number, suggesting in this tumor subtype, where there is higher prognostic/diagnostic value, has the MF presence. 
NON DUCTAL INVASIVE CARCINOMAS

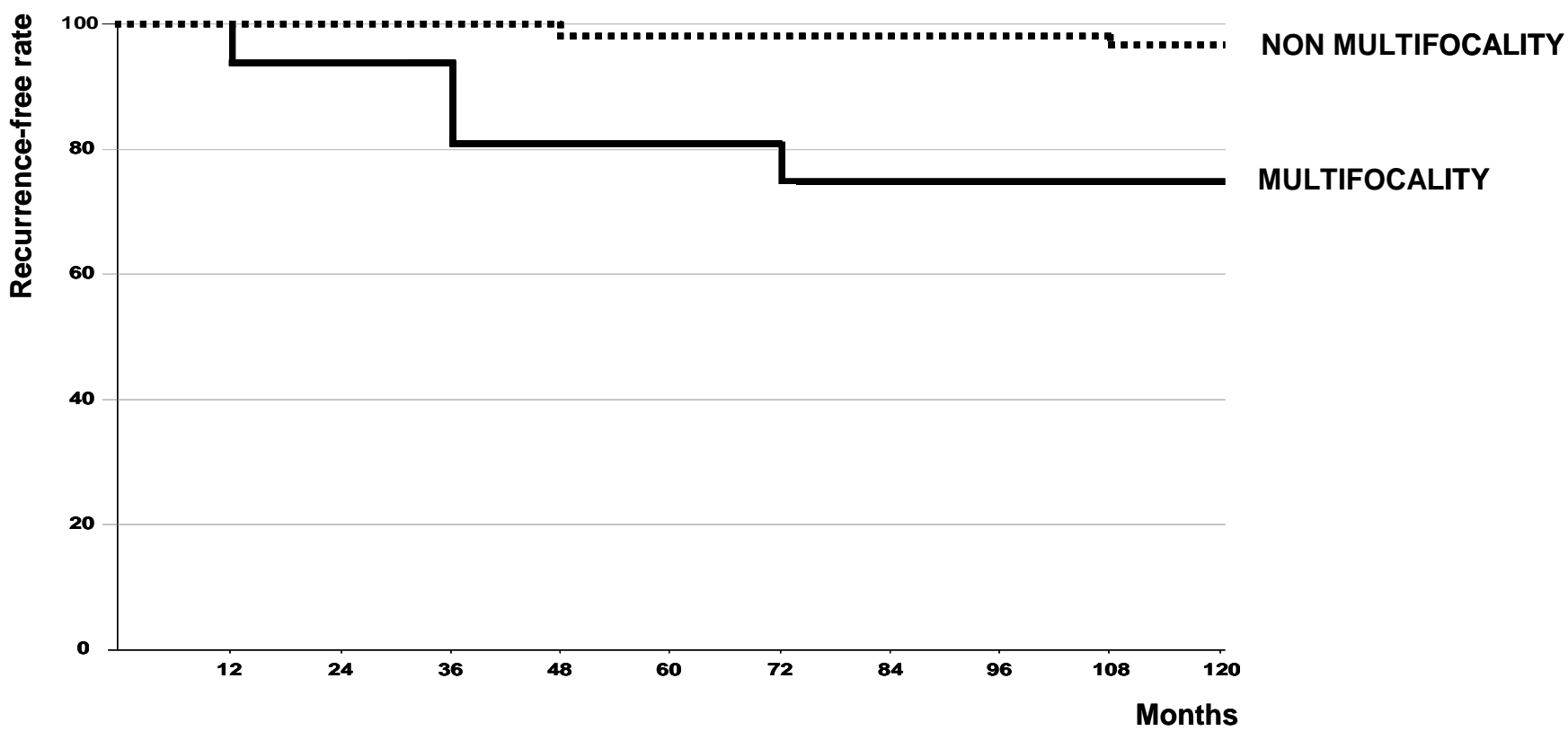

Fig. (1). Recurrence-free survival rates with and without multifocality in patients with non-ductal invasive carcinoma. A significant association between multifocality and recurrence free-rate was shown.

\section{ACKNOWLEDGEMENT}

Declared none.

\section{CONFLICT OF INTEREST}

The authors confirm that this article content has no conflict of interest.

\section{REFERENCES}

[1] Harris L, Fritsche H, Mennel R, et al. American Society of Clinical Oncology 2007 update of recommendations for the use of tumor markers in breast cancer. J Clin Oncol 2007; 25: 5287-312.

[2] Mook S, Schmidt MK, Weigelt B, et al. The 70-gene prognosis signature predicts early metastasis in breast cancer patients between 55 and 70 years of age. Ann Oncol 2010; 21: 717-22.

[3] Karanikas G, Koronakis N, Lagoudianakis EE, et al. The value of proliferation indexes in breast câncer. Eur J Gynaecol Oncol 2010; 31: 181-4.

[4] Tai P, Yu E, Joseph K. Prognostic significance of number of positive nodes: a long-term study o fone to two nodes versus three nodes in breast câncer. Int J Radiat Oncol Biol Phys 2010; 77: 1807.

[5] Schnitt SJ. Classification and prognosis of invasive breast câncer: from morphology to molecular taxonomy. Mod Pathol 2010; 23(Suppl 2): s60-4.

[6] Lemée F, Bergoglio V, Fernandez-Vidal A, et al. DNA polymerase theta up-regulation is associated with poor survival in breast cancer, perturbs DNA replication, and promotes genetic instability. Proc Natl Acad Sci USA 2010; 107: 13390-5.

[7] Albain KS, Barlow WE, Shak S, et al. Prognostic and predictive value of the 21-gene recurrence score assay in pstomenopausal women with node-positive, oestrogen-receptor positive breaat cancer on chemotherapy: a retrospective analysis of a randomised Trial. Lancet Oncol 2010; 11: 55-65.

[8] Katz A, Strom E, Buchholz T, Theriault R, Singletary Em McNeese M. The influence of pathologic tumor characteristics on locoregional recurrence rates following mastectomy. Int J Radiat Oncol Biol Phys 2001; 50: 735-42.
[9] Joergensen LE, Gunnarsdottir KA, Lanng C, Moeller S, Rasmussen BB. Multifocality as a prognosrtic factor in breast cancer patients registered in Danish Breast Cancer cooperative Group (DCCG) 1996-2001. Breast 2008; 17: 587-91.

[10] Coombs NJ, Boyages J. Multifocal and multicentric breast cancer: does each focus matter? J Clin Oncol 2005; 23: 7497-502.

[11] Andea AA, Bouwman D, Wallis T, Visscher DW. Correlation of tumor volume and surface area with lymph node status in patients with multifocal/multicentric breast carcinoma. Cancer 2004; 100: 20-7.

[12] Boyages J, Jayasinghe UW, Coombs N. Multifocal breast cancer and survival: each focus does matter particularly for larger tumours. Eur J Cancer 2010; 46: 1990-6.

[13] Nakamura R, Song JP, Isogaki J, Kitayama Y, Sugimura H. Multiple (multicentric and multifocal) cancers in the ipsilateral breast with different histologies: profiles of chromosomal numetic abnormality. Jpn J Clin Oncol 2003; 33: 463-9.

[14] Bendifallah S, Werkoff G, Borie-Moutafoff C, et al. Multiple synchronous (multifical and multicentric) breat cancer: clinical implications. Surg Oncol 2010; 19(4): e115-23.

[15] Berg WA, Gilbreath PL. Multicentric and multifocal cancer: whole-breast US in preoperative evaluation. Radiology 2000; 214 59-66.

[16] Breast, In American Joint Committee on Cancer. AJCC. Cancer Staging Manual. $6^{\text {th }}$ ed. New York, NY: Springer 2002; pp. 171-80.

[17] Jürgensen M, Chacon R, Baeza C, Riveros R. Cánceres de mama multifocales-multicéntricos: ¿son realmente de peor pronóstico? Rev Chilena de Cirugía 2009; 61: 125-30.

[18] Pedersen L, Gunnarsdottir KA, Rasmussen BB, Moeller S, Lanng C. The prognostic influence of multifocality in breast cancer patients. Breast 2004; 13: 188-93.

[19] Wilkinson LS, Given-Wilson R, Hall T, Potts H, Sharma AK, Smith E. Increasing the diagnosis of multifocal primary breast cancer by the use of bilateral whole-breast ultrasound. Clin Radiol 2005; 60: 573-8.

[20] Olivas-Maguregui S, Villaeñor-Navarro Y, Ferrari-Carballo T, et al. Importance of the preoperative evaluation of multifical and multicentric breast cancer with magnetic resonante Imaging in women with dense paranchyma. Rev Invest Clin 2008; 60: 382-9. 
[21] Elshof LE, Rutgers EJ, Deurloo EE, et al. A practical approach to mange additional lesions at preoperative breast MRI in patients elegible for breast conserving therapy: results. Breast Cancer Res Treat 2010; 124(3): 707-15.

[22] Litton J, Eralp Y, Gonzalez-Angulo A, et al. Multifocal breast cancer in women $</=35$ years old. Cancer 2007; 110: 1445-50.

[23] Garimella V, Long ED, O'Kabe SL, Drew PJ, Cawkwell L. Oestrogen and progesterone receptor status of individual foci in multifocal invasive breast cancer. Acta Oncol 2007; 46: 204-7.

[24] Cabioglu N, Ozmen V, Kaya H, et al. Increased lymph node positivity in multifocal and multicentric breast cancer. J Am Coll Surg 2009; 208: 67-74.

[25] Oh J, Dryden M, Woodward W, et al. Locoregional control of clinically diasgnosed multifocal or multicentric breast cancer after neoadjuvant chemotherapy and locoregional therapy. J Clin Oncol 2006; 24: 4971-75.

[26] Yerushalmi R, Kennecke H, Woods R, Olivotto IA, Speers C, Gelmon KA. Does multicentric/multifocal breast cancer differ from unifocal breast cancer?, An analysis of survival and contralateral breast cancer incidence. Breast Cancer Res Treat 2009; 117: 36570 .

[27] Weissenbacher TM, Zszhage M, Janni W, et al. Multicentric and multifocal versus unifical breast cancer: is the tumor-nodemetastasis classification justified? Breast Cancer Res Treat 2010; 122: $27-34$.

[28] Dedes KJ, Fink D. Clinical presentation and surgical management of invasive lobular carcinoma of the breast. Breast Dis 2009; 30: $31-7$.

Received: June 27, 2012

(C) Ruibal et al.; Licensee Bentham Open.

This is an open access article licensed under the terms of the Creative Commons Attribution Non-Commercial License (http://creativecommons.org/licenses/by-nc/ $3.0 /$ ) which permits unrestricted, non-commercial use, distribution and reproduction in any medium, provided the work is properly cited. 